\title{
Illuminance levels based on different sky conditions by considering daylight harvesting
}

\author{
Nik Sahidah Nik Ahmad, Nur Hanis Mohammad Radzi, Mohd Noor Abdullah \\ Green and Sustainable Energy Focus Group (GSEnergy), Faculty of Electrical and Electronic Engineering, \\ Universiti Tun Hussein Onn Malaysia, Malaysia
}

\begin{tabular}{|c|c|}
\hline Article Info & ABSTRACT \\
\hline Article history: & \multirow{10}{*}{$\begin{array}{l}\text { Daylight Harvesting Systems (DHS) offer the most effective and significant } \\
\text { to reduce energy consumption. In the lighting system, there are various } \\
\text { problems which include waste of energy consumption, inappropriate lighting } \\
\text { and increasing greenhouse effect. Therefore, the waste of energy } \\
\text { consumption should be reduced by controlling the dimming levels of } \\
\text { artificial lighting according to the standard thus reducing the greenhouse } \\
\text { effect. Hence, this paper considered the daylight adaptive for the lighting } \\
\text { system to determine the dimming level and illuminance level for the office } \\
\text { room. The simulation has been carried out using DIALux simulation lighting } \\
\text { software to simulate the average daylight and average illuminance level with } \\
\text { different conditions sky, which is clear, average, and overcast sky. Based on } \\
\text { the result, the illuminance level has complied with the European Standard } \\
\text { EN12464-1. Furthermore, the presence of daylight and weather conditions } \\
\text { plays an essential role in the lighting system. The illuminance and dimming } \\
\text { levels are different depending on the time and type of sky condition at that } \\
\text { time. Therefore, the daylight adaptive in the lighting system can reduce } \\
\text { the use of artificial light in the room. }\end{array}$} \\
\hline Received Jan 2, 2020 & \\
\hline Revised Apr 5, 2020 & \\
\hline Accepted Apr 17, 2020 & \\
\hline Keywords: & \\
\hline Daylight harvesting & \\
\hline Dimming level & \\
\hline Illuminance level & \\
\hline Lighting system & \\
\hline & \\
\hline
\end{tabular}

Copyright @ 2020 Institute of Advanced Engineering and Science. All rights reserved.

\section{Corresponding Author:}

Nur Hanis Mohammad Radzi,

Green and Sustainable Energy Focus Group (GSEnergy),

Faculty of Electrical and Electronic Engineering,

Universiti Tun Hussein Onn Malaysia, 86400 Parit Raja, Batu Pahat, Johor, Malaysia.

Email: nurhanis@uthm.edu.my

\section{INTRODUCTION}

Nowadays, the demand for energy consumption has rapidly increased and developed over the world. Energy demand in the building is increasing, particularly in energy used for heating, lighting, ventilation, and air conditioning (HVAC). In Malaysia, buildings consumed 48 percent of the country's electricity generated [1]. Commercial buildings use over 30 percent of the primary energy total [2]. It is estimated that electric lighting constitutes 20-40 percent of the total energy used in buildings. Consequently, it can raise greenhouse gas emissions with severe global impacts such as global warming and climate change [3, 4]. Appropriate control strategies can achieve significant energy savings for lighting systems.

Recently, energy saving in the building is the main objective among researchers due to the issue that gives a big impact on the world which is global warming [5]. The achievement of energy savings and the pleasing convenience of consumer lighting are two major factors when developing lighting systems. Furthermore, adequate lighting can give occupants comfort in doing their works. It can be divided into two in the lighting system, which is artificial light and natural illumination. Based on the statistical data provided by the International Energy Agency (IEA), about 19 percent of global electricity consumption was captured in the percentage of artificial lighting use [6]. The lighting system offers several options for cost-effective energy savings, and one of the common practices is the implementation of energy management in lighting systems $[7,8]$. 
Daylight is a lighting medium that suits the human visual response most closely. The natural illumination is by capturing daylight, which can be obtained through windows, skylights, light shelves, and others. The natural illumination is used to reduce the use of artificial lighting in buildings called daylight harvesting [9]. The main challenge for daylight harvesting is to provide some amount of reliable indoor lighting, combined with natural sunlight that is not a stable source of light [10]. The daylight harvesting system generally divides by two, which is a photo-sensor and controller. The photo-sensor is used to measure the illuminance levels meanwhile, the controller uses the photo-sensor measurements to adjust the electrical lights $[11,12]$.

Daylight Harvesting Systems (DHS) offer the most effective energy saving with adjusting the lights automatically depending on the amount of daylight in a room space [13]. Furthermore, it may help to reduce one-third of the total energy costs for buildings with reducing the electricity used for artificial lighting that can mitigate greenhouse gas emissions $[14,15]$. Lighting systems are a significant factor in the comfort of workplaces, allow employees to be healthier, and have a lower rate of absenteeism and be more productive [16]. The lighting requirements vary in different work environments, and different types of lighting are required to conduct different types of work. Additionally, insufficient light intensity can cause severe problems for occupants. It can influence the use of energy where the source of electrical light generates light intensity that exceeds the desired quantity and is not suitable for work.

The major problem occurs when artificial light cannot be changed manually or automatically at the dimming level in the office, hall, or meeting room to regulate the illuminance level according to the lighting standards, which are European Standard EN12464-1 [17]. The dimming control is necessary to minimize the illuminance levels of artificial light in order to fulfill the illumination standard. In the lighting system, the main objective is to minimize the dimming levels. Therefore, the energy consumption for artificial light will decrease and energy savings will occur in order to mitigate global warming.

According to previous research, the average light energy savings achieved by responsive daylight is around 60-80 percent [18]. In recent works [19], consider the daylight and occupancy adaptive for smart lighting control to determine dimming levels to saving energy by using the occupancy sensor at clear sky condition. In [20], by optimizing the dimming level, it can minimize the use of artificial light by the proposed iterative method. Furthermore, energy saving up to 34 percent when minimize the dimming level by using an artificial neural network (ANN) method [21]. There have several strategies that can be implemented in the lighting system for reducing energy consumption, such as occupancy and daylight-linked controls [22]. In the smart technology that used in the lighting system control, the use of smart devices such as sensors is very important either dim the lamp automatically or the lamp automatically will be closed when not detect motion or temperature in the room. Therefore, using the occupancy sensor to save the energy consumption and daylight sensor used to measure the illuminance level [23-25].

In this paper, the illuminance levels are considering based on the European Standard EN12464-1 to ensure fulfill visual comfort and performance needs. The case study area was the office room at the QA Block, Faculty of Electrical and Electronic Engineering (FKEE), UTHM. The case study will be modeled using DIALux simulation lighting software. Then, the result obtained will analyze the illuminance level and dimming level from daylight source based on different sky conditions which are the clear, average and overcast sky.

\section{SIMULATION SETUP}

The illuminance level proposed in the European Standard EN12464-1 with minimum illuminance level which is 500 lux and above. The requirement of the illuminance level is for the actual work area instead of the entire room. All process in order to get the simulation result for illuminance and dimming level was visualized in the flowchart below. The process has explained and described in detail in the flowchart and completed this simulation using DIALux lighting simulation software with considering different types of sky condition which is a clear, average and overcast sky. Figure 1 shows the flowchart the summarization of the simulation for illuminance and dimming levels that have been used in this research.

The case study area was an office room located at the QA Block, Faculty of Electrical and Electronic Engineering (FKEE), Universiti Tun Hussein Onn Malaysia. The dimensions of an office are 5.6 $\mathrm{m}$ (length), $3 \mathrm{~m}$ (ceiling height), and $4 \mathrm{~m}$ (wide). The office space is lit with light-emitting diode (LED) lamps because of the benefits of the lamps such as energy savings, energy efficiency, high luminous efficacy, controllable, long lifetime and environmentally friendly compared to fluorescent lamps.

The specification of the LED lamps used in the office room is recessed type, total luminous flux $4200 \mathrm{~lm}$, and total connected load $39.5 \mathrm{~W}$. The lighting has added 4 LED luminaires and will be considered the various sky conditions which are the clear, average and overcast sky. The illuminance and dimming levels for this case study area were simulated using DIALux simulation lighting software. The top and side view of an office room is shown in Figure 2 and Figure 3. 


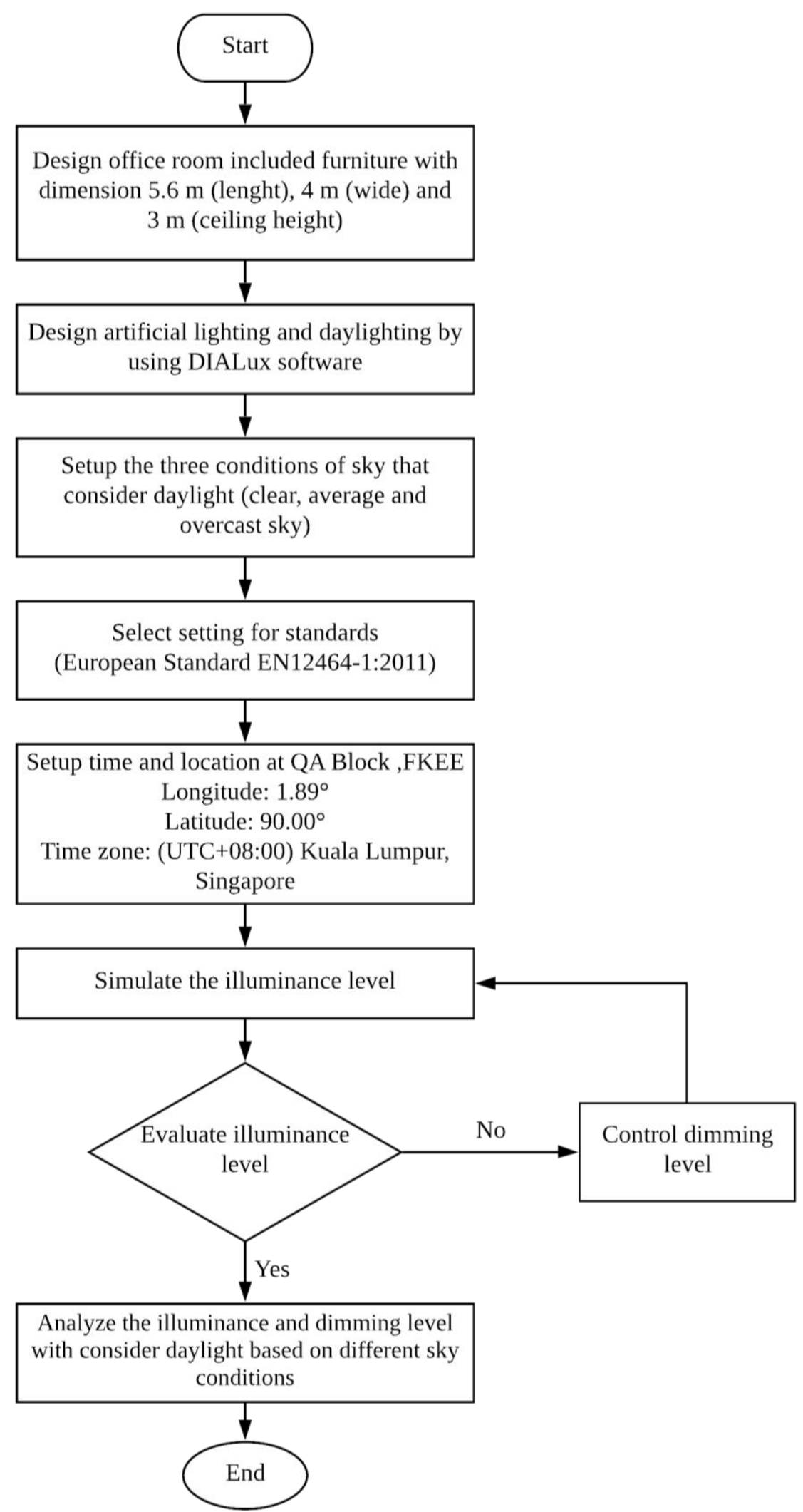

Figure 1. The summarization of the simulation for illuminance and dimming levels 


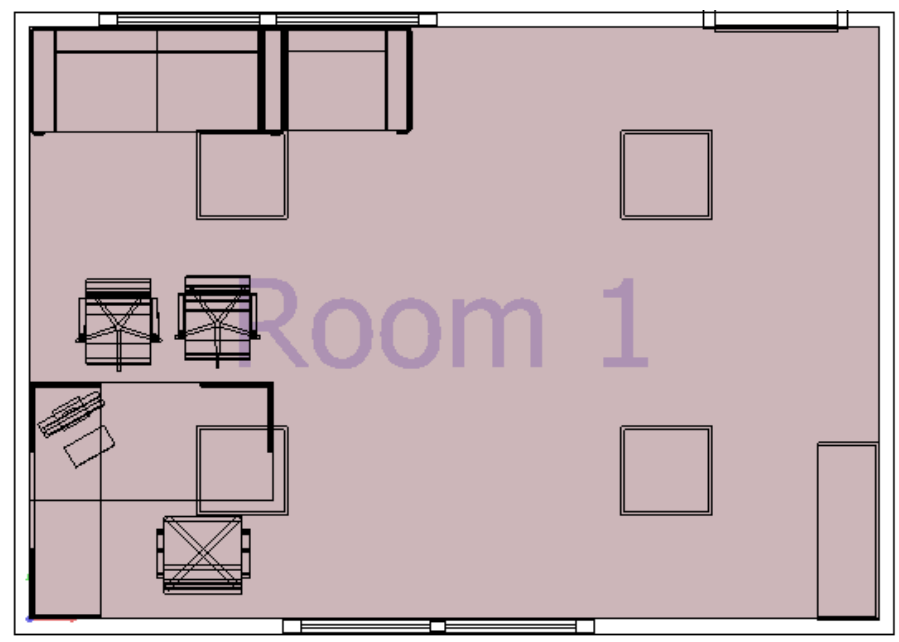

Figure 2. Top view of an office room

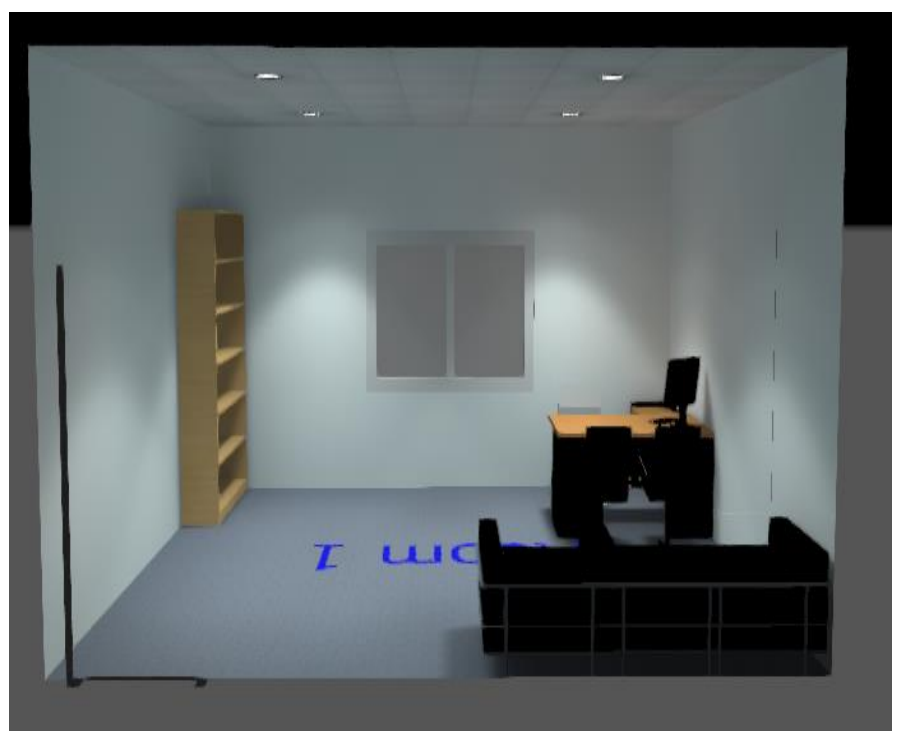

Figure 3. Side view of an office room

\section{RESULTS AND ANALYSIS}

In this study, the average daylight was simulated using DIALux simulation lighting software under clear, average and overcast sky conditions. The simulation of average daylight is taken during office hours between 08:00 to 17:00 on the first day of September for 2019 with different sky conditions. Figure 4 shows the simulation results average daylight illuminance with different sky conditions, which are the clear, average, and overcast sky in the office room. Based on simulation results, the illuminance level can change according to weather and time. It is also possible that daylight change also depends on the movement of the sun itself. At the clear sky, the illuminance from daylight is highest between other conditions, which are an average and overcast sky. For average sky condition, the lowest average daylight illuminance is at time 14:00 due to little presence of daylight. The lowest illuminance from daylight is an overcast sky and the average of daylight illuminance at that condition is remain the same from time 08:00 until 17:00.

Figure 5 shows the result for the average illuminance level with different sky conditions in the office room, which consider daylight harvesting. The illuminance level considers daylight more efficient and can reduce energy consumption. The average illuminance level at the clear sky is higher due to the bright condition of the sky and the presence of high sunlight compared to the average and overcast sky. 


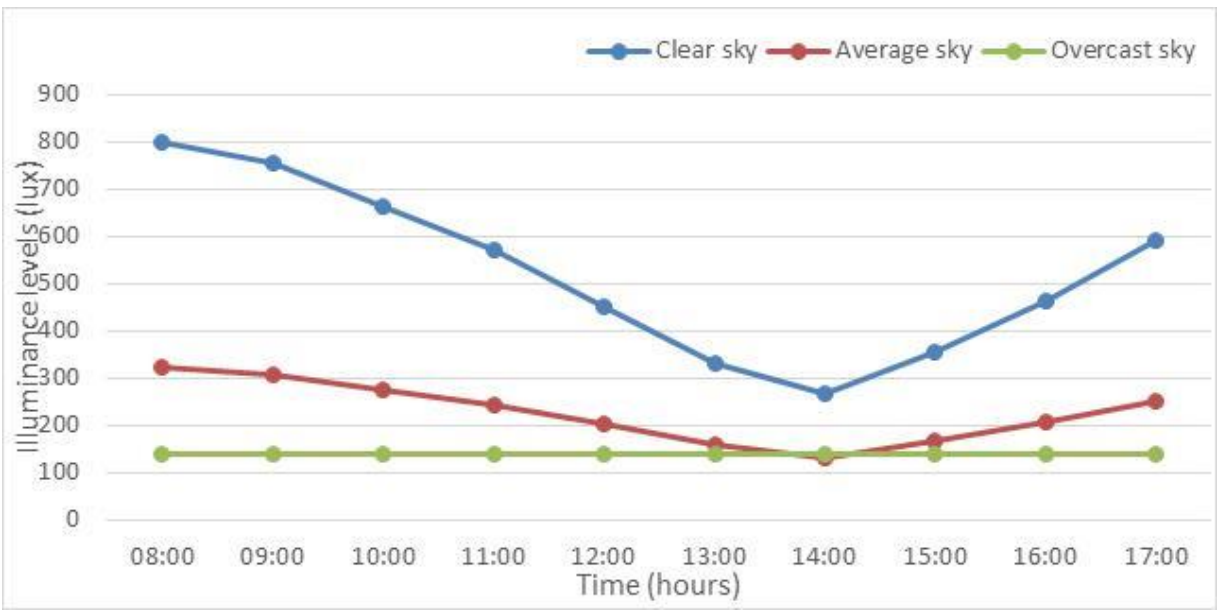

Figure 4. Average daylight illuminance with different sky conditions in the office room

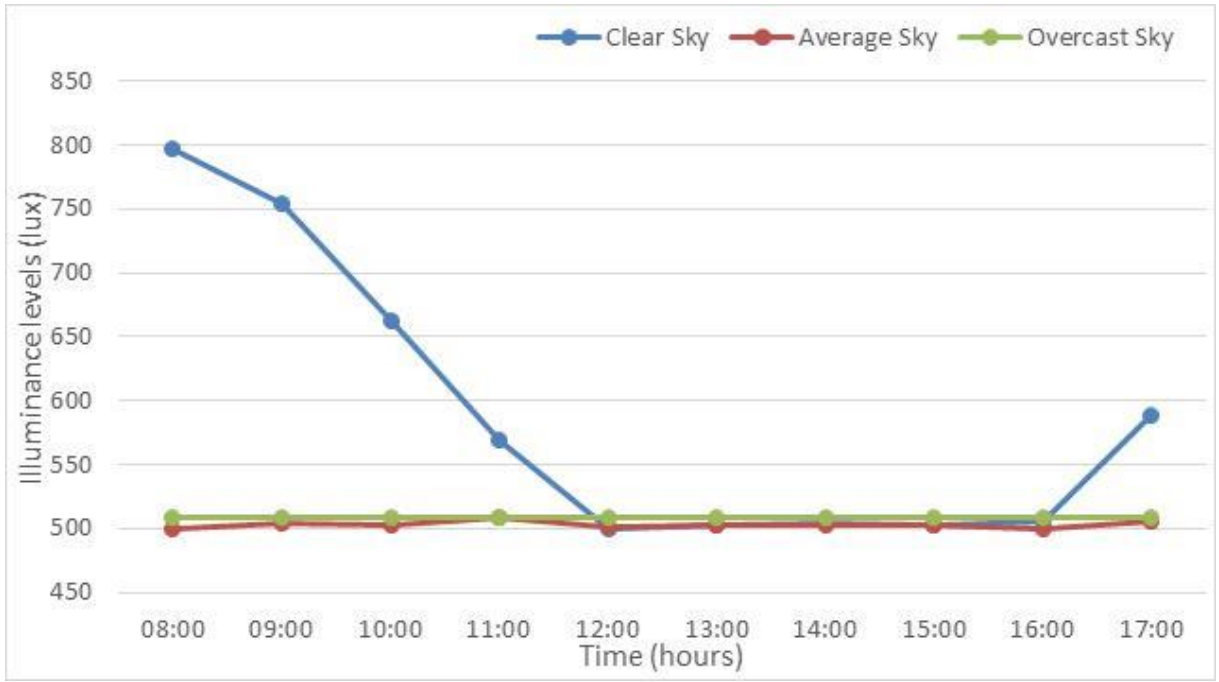

Figure 5. Average illuminance level with different sky conditions in the office room

Table 1 until Table 3 shows the result of illuminance and dimming level with different conditions of the sky. From Table 1, it can be seen that the highest dimming level which is 0.47 at times 14:00 due to the illuminance from daylight entered the room are lowest compared to other times for clear sky condition. Then, there have several times that no need to dim and open the artificial light due to the highest illuminance from daylight across the room, which is at time 08:00 until 11:00 and 17:00. The illuminance level at that time was fulfilled the European standard EN12464-1, which is 500 lux and above.

Meanwhile, Table 2 shows the simulation result of the illuminance and dimming level for the average sky. The average sky dimming level is more than 0.35 , which means the artificial light had to dim more than 0.35 to reach the 500 lux specification and illuminance requirement. At the time 14:00, the dimming level is higher than others due to the lowest illuminance of the contribution. Table 3 shows the result of illuminance and dimming levels for an overcast sky. For the overcast sky, the illuminance and dimming level remain the same, which is 503 lux and 0.73 dimming level from 08:00 until 17:00 due to the illuminance from the daylight at this sky condition are lowest. This indicates that the presence of daylight and weather conditions play an important role in the lighting system.

Based on the result from Table 1 until Table 3, it can be concluded that the differences in the sky and the brightness of the sky have a significant impact on the lighting conditions. The darker the sky, the higher the use of artificial light needed for the lighting system. Furthermore, this proves that with the adaptive daylight, it can reduce the use of artificial light. 
Table 1. The illuminance and dimming levels for clear sky

\begin{tabular}{ccc}
\hline Time & $\begin{array}{c}\text { Illuminance levels } \\
\text { (lux) }\end{array}$ & Dimming Levels \\
\hline $8: 00$ & 797 & 0 \\
$9: 00$ & 754 & 0 \\
$10: 00$ & 663 & 0 \\
$11: 00$ & 570 & 0 \\
$12: 00$ & 500 & 0.10 \\
$13: 00$ & 503 & 0.35 \\
$14: 00$ & 505 & 0.47 \\
$15: 00$ & 503 & 0.29 \\
$16: 00$ & 506 & 0.10 \\
$17: 00$ & 589 & 0 \\
\hline
\end{tabular}

Table 2. The illuminance and dimming levels for average sky

\begin{tabular}{ccc}
\hline Time & $\begin{array}{c}\text { Illuminance levels } \\
\text { (lux) }\end{array}$ & Dimming Levels \\
\hline $8: 00$ & 500 & 0.35 \\
$9: 00$ & 504 & 0.38 \\
$10: 00$ & 503 & 0.45 \\
$11: 00$ & 508 & 0.52 \\
$12: 00$ & 501 & 0.59 \\
$13: 00$ & 503 & 0.68 \\
$14: 00$ & 503 & 0.73 \\
$15: 00$ & 503 & 0.66 \\
$16: 00$ & 500 & 0.58 \\
$17: 00$ & 506 & 0.50 \\
\hline
\end{tabular}

Table 3. The illuminance and dimming levels for overcast sky

\begin{tabular}{ccc}
\hline Time & $\begin{array}{c}\text { Illuminance levels } \\
(\text { lux })\end{array}$ & Dimming Levels \\
\hline $8: 00$ & 503 & 0.73 \\
$9: 00$ & 503 & 0.73 \\
$10: 00$ & 503 & 0.73 \\
$11: 00$ & 503 & 0.73 \\
$12: 00$ & 503 & 0.73 \\
$13: 00$ & 503 & 0.73 \\
$14: 00$ & 503 & 0.73 \\
$15: 00$ & 503 & 0.73 \\
$16: 00$ & 503 & 0.73 \\
$17: 00$ & 503 & 0.73 \\
\hline
\end{tabular}

\section{CONCLUSION}

This paper has presented the illumination and dimming level with different sky conditions, which are the clear, average, and overcast sky using DIALux simulation lighting software. In this paper, the illuminance and dimming level are different due to the weather and time correspond to the type of sky condition at that time. The results show that suitable illuminance is needed to give comfort for occupancy based on the working area and scope of works. Based on that, dimming control is significant to ensure the illuminance level will be minimized and fulfill the standard of illumination.

\section{ACKNOWLEDGEMENTS}

The authors would like to thanks the Ministry of Education Malaysia for supporting this research. This work was supported by Universiti Tun Hussein Onn Malaysia (UTHM) under Fundamental Research Grant Scheme Ref No. FRGS/1/2018/TK07/UTHM/02/3.

\section{REFERENCES}

[1] J. S. Hassan, et al., "Building energy consumption in Malaysia: An overview," Jurnal Teknologi, vol. 70, no. 7, pp. 33-38, 2014.

[2] J. Liu, et al., "Fuzzy logic controller for energy savings in a smart LED lighting system considering lighting comfort and daylight," Energy and Buildings, vol. 127, pp. 95-104, 2016.

[3] B. J. van Ruijven, et al., "Amplification of future energy demand growth due to climate change," Nature Communications, vol. 10, no. 1, pp. 1-12, 2019.

[4] P. H. Shaikh, et al., "A review on optimized control systems for building energy and comfort management of smart sustainable buildings," Renewable and Sustainable Energy Reviews, vol. 34, pp. 409-429, 2014.

[5] A. M. Al-Ghaili, et al., "A Review on Building Energy Savings Strategies and Systems (BE3S)," 2019 IEEE 2nd International Conference on Power and Energy Applications (ICPEA), pp. 243-249, 2019.

[6] Y. Gao, et al., "Daylighting Simulation and Analysis of Buildings with Dynamic Photovoltaic Window Shading Elements," 2017 14th China International Forum on Solid State Lighting: International Forum on Wide Bandgap Semiconductirs China, pp. 52-55, 2017.

[7] A. A. El-khalek, et al., "Opportunities of energy saving in lighting systems for public buildings," Renewable Energy and Sustainable Development, vol. 3, no. 1, pp. 95-98, 2017.

[8] M. F. Lee and N. Q. Zulkafli, "A case study on energy saving through lighting system for building: An internal energy review," PECON 2016 - 2016 IEEE International Conference on Power Energy, pp. 575-579, 2016. 
[9] C. P. Kurian, et al., "Office Lighting Simulation: Energy implications with scheduled occupancy and daylight harvesting," 2018 International Conference on Control, Power, Communication and Computer Technologies (ICCPCCT), pp. 129-135, 2018.

[10] X. Li, et al., "Design and analysis of an active daylight harvesting system for building," Renewable Energy, vol. 139, pp. 670-678, 2019.

[11] R. Kumar, "New Algorithms for Daylight Harvesting in a Private Office," 2015 18th International Conference on Information Fusion, pp. 383-392, 2015.

[12] K. S. Rambhad, "Daylight Harvesting System: A Review on Light Harvesting Technologies in Commercial Buildings," International Journal of Analytical, Experimental and Finite Element Analysis (IJAEFEA), vol. 1, no. 4, pp. 13-17, 2014.

[13] N. Gentile, et al., "Daylight harvesting control system design recommendations based on a literature review," 2015 IEEE 15th International Conference on Environment and Electrical Engineering (EEEIC), pp. 632-637, 2015.

[14] F. Tan, D. Caicedo, A. Pandharipande, and M. Zuniga, "Sensor-driven, human-in-the-loop lighting control," Light. Res. Technol., vol. 50, no. 5, pp. 660-680, 2018.

[15] G. Lim, et al., "Daylight performance and users ' visual appraisal for green building offices in Malaysia," Energy and Buildings, vol. 141, pp. 175-185, 2017.

[16] C. De Bakker, M. Aries, H. Kort, and A. Rosemann, "Occupancy-based lighting control in open-plan office spaces : A state-of-the-art review," Build. Environ., vol. 112, pp. 308-321, 2017.

[17] BSI Standards Publication Light and lighting, "Lighting of work places Part 1: Indoor work places," European committee for standardization, pp. 1-57, 2011.

[18] I. T. Kim, et al., "Advanced dimming control algorithm for sustainable buildings by daylight responsive dimming system," Sustainability, vol. 10, no. 11, pp. 4087-4101, 2018.

[19] D. Caicedo and A. Pandharipande, "Daylight and occupancy adaptive lighting control system: An iterative optimization approach," Lighting Research and Technology, vol. 48, no. 6, pp. 661-675, 2015.

[20] D. Caicedo and A. Pandharipande, "Sensor-Driven Lighting Control with Illumination and Dimming Constraints," IEEE Sensors Journal, vol. 15, no. 9, pp. 5169-5176, 2015.

[21] K. R. Wagiman and M. N. Abdullah, "Intelligent lighting control system for energy savings in office building," Indonesian Journal of Electrical Engineering and Computer Science, vol. 11, no. 1, pp. 195-202, 2018.

[22] M. C. Dubois, et al., "Retrofitting the Electric Lighting and Daylighting Systems to Reduce Energy Use in Buildings: A Literature Review," Energy Research Journal, vol. 6, no. 1, pp. 25-41, 2015.

[23] A. Khosrowpour, et al., "A review of occupant energy feedback research: Opportunities for methodological fusion at the intersection of experimentation, analytics, surveys and simulation," Applied Energy, vol. 218, pp. 304-316, 2018.

[24] K. R. Wagiman, et al., "A review on sensing-based strategies of interior lighting control system and their performance in commercial buildings," Indonesian Journal of Electrical Engineering and Computer Science, vol. 16, no. 1, pp. 208-215, 2019.

[25] L. T. Doulos, et al., "Harvesting daylight with LED or T5 fluorescent lamps? The role of dimming," Energy and Buildings, vol. 140, pp. 336-347, 2017.

\section{BIOGRAPHIES OF AUTHORS}
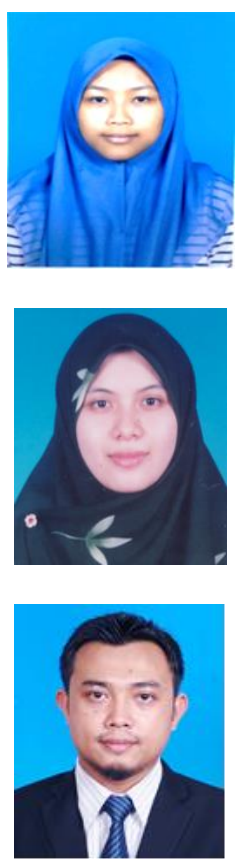

Nik Sahidah Nik Ahmad currently pursuing the Master Degree in Electrical Engineering at Universiti Tun Hussien Onn Malaysia, Batu Pahat, Johor, 2020.

Nur Hanis Mohammad Radzi received her B.Eng. and M.Eng in Electrical Engineering (Power) from Universiti Teknologi Malaysia (UTM) in 2005 and 2009 respectively. She also received Ph.D from The University of Queensland, Brisbane, Australia in 2012. Currently, she is a senior lecturer in the Faculty of Electrical \& Electronic Engineering at Universiti Tun Hussein Onn Malaysia (UTHM). Her research interests include transmission pricing, power system economics, energy management and renewable energy.

Mohd Noor Abdullah received his B.Eng. (Hons) in Electrical Engineering and M. Eng. in Electrical Engineering (Power System) from Universiti Teknologi Malaysia (UTM) in 2008 and 2010 respectively. He also received a Ph.D degree in Electrical Engineering from University of Malaya (UM) in 2014. He has been with Universiti Tun Hussein Onn Malaysia (UTHM) from 2008 to 2014 as a tutor. He is currently as a Lecturer in Department of Electrical Power Engineering, FKEE, UTHM. He also appointed as a head of Green and Sustainable Energy (GSEnergy) Focus Group in FKEE, UTHM. His research interests include electric power dispatch, distributed generation, renewable energy and meta-heuristic optimization techniques. 